\title{
Effect of Selenium and Zinc Supplementation on Hypothyroidism in Rats
}

\author{
Hoda S. Ibrahim, Naeem M. Rabeh, ALshymaa A. Sharaf ELden \\ Nutrition and Food Science Dept., Faculty of Home Economics, \\ Helwan University, Cairo, Egypt.
}

\begin{abstract}
The aim of the present study was to investigate the effect of selenium and zinc supplementation on thyroid hormones (THs) in rats suffering from hypothyroidism (HT). Forty eight adult male albino rats (200 \pm 7 g) were divided in two main groups. The first main group $(n=6)$ was a -ve control, the second main group $(n=42)$ was injected with PTU to induce HT. Then, these rats were divided into seven subgroups, subgroup one was fed on basal diet as a positive control; subgroups 2 -3 were fed on basal diet supplemented with sodium selenate at two levels. While subgroups 4-5 were fed on basal diet supplemented with zinc carbonate at two levels. Subgroups $6-7$ were fed on basal diet supplemented with the combination of sodium selenate and zinc carbonate. At the end of the experimental period (6 weeks), rats were sacrificed to get serum. Biochemical analysis of serum THs, Se, Zn and GPx were determined. The results indicated that PTU treated rats showed significant reduction in FT4 and FT3 levels, however, TSH level was significantly increased compared to the (ve) control group. Administration of Se and /or Zn in the diet at the two levels of intake caused an improving in HT status as related to significant increase in the concentration of both FT4 and FT3 levels and significant reduction in the level of TSH. Also, the weight of thyroid gland was significantly decreased compared to the positive control group. Also, it was observed that the serum concentrations of Se, Zn and GPx were significantly increased for all treated groups. Histopathological examination revealed that PTU treated rats showed an enlarged and dilated thyroid follicles lined with flattened epithelium and congested capilleries. Administration of Se and Zn at the two combination levels of intake showed no histopathological changes when compared to the control (-ve) group. In conclusions, diet supplemented with combination of Se and Zn at the tested levels resulted in an improvement of biochemical and histological changes resulted from HT. It could be suggested that $\mathrm{Zn}$ and Se at the tested levels could be used as a suitable supplementation therapy for hypothyroid patients.
\end{abstract}

Keywords: Selenium, Zinc, Hypothyroidism, Thyroid hormone, Histological examination, GPX.

\section{INTRODUCTION}

Thyroid diseases are more common in females than in males (Garber, et al., 2012). These diseases are either due to thyroid gland over activity resulting in hyperthyroidism or under activity resulting in hypothyroidism (HT) (Fabrizio, 2003). Thyroid function is affected by various physiological conditions, for instance, pollutants (Mahjoubi-Samet, et al., 2005), food deprivation (Fetoui, et al., 2006), iodine deficiency (Zimmermann, 2008) and antithyroid drugs (Ghorbel, et al., 2008). These compounds are able to interfere, directly or indirectly, with the synthesis of thyroid hormones (TH) which fundamentally determine the development and growth of many organs (Beckett and Arthur, 1994).

Hypothyroidism is a common disorder of the endocrine system in which the thyroid gland does not produce enough TH. Hypothyroidism characterized by a reduction in metabolic rate which results in adverse effect on many organs and system activities (Golden et al., 2009). Hypothyroidism subjects diagnoses with biochemical parameters of thyroxine (T4) and triiodothyronine (T3) levels are low and thyroid-stimulating hormone (TSH) levels are high (Dons, et al., 2009). Normal thyroid status is dependent on the presence of many trace elements [iodine, zinc ( $\mathrm{Zn})$, selenium (Se), copper and iron] for both the synthesis and metabolism of TH. Deficiency of these can result in HT (Betsy, et al., 2013).

Selenium is probably the next most important mineral (after iodine) affecting thyroid function. Selenium also plays an important role in the control of THs metabolism. The enzyme responsible for 
the conversion of the hormone T4 to its active form, T3, is a selenoprotein called iodothyronine deiodinase (The British Nutrition Foundation, 2001). While Se dependent glutathione peroxidases (GPx) are implicated in gland protection (Rayman, 2000).

Formigari, et al., (2007) and Catania, et al., (2009) reported that, $\mathrm{Zn}$ is a known fundamental component of the endogenous enzymatic antioxidant system with antioxidant properties. It is required for optimum performance, growth. Zinc is also necessary for optimal activity of many hormones, including TH (Maxwell and Volpe, 2007). Zinc is not only required for cell-mediated immunity, but also an effective antioxidant and anti-inflammatory agent (Prasad, 2013). Zinc is required for the T3 receptor to adopt its biologically active confirmation. Some of the effects of $\mathrm{Zn}$ deficiency may be due to loss of $\mathrm{Zn}$ from the T3 receptor and impairment of $\mathrm{T} 3$ action (Freake, et al., 2001).Thus, the aim of the present study was to investigate the effect of selenium and zinc supplementation on thyroid hormones (THs) in rats suffering from hypothyroidism (HT)

\section{Materials ANd Methods}

\section{Materials}

Propylthiouracil and TWEEN 20 (dissolving substance) were obtained from Amoun Pharmaceutical Company, El-Obour City, Egypt. Vitamins, choline bitartrate and L-cysteine were obtained from the Cairo Company for Chemicals Trading, Cairo, Egypt. Sodium selenate, zinc carbonate, other minerals, casein and cellulose were obtained from El-Gomhorya Pharmaceutical Company, Cairo, Egypt. Kits for blood analysis were purchased from local distributer (Sigma chemical) Cairo, Egypt. Adult male albino rats (Sprague-Dawley strain) weighing approximately (200 $\pm 7 \mathrm{~g})$ were purchased from Experimental Animals Station, Agricultural Research Center, Giza, Egypt.

\section{Methods:}

\section{Induction of Hypothyroidism in Rats:}

Hypothyroidism was induced in normal healthy adult male rats according to Sener, et al., (2006) using PTU (10 mg/kg BW/day by intraperitoneal (I.P) for 15 day). PTU injections were repeated once daily. Then, blood samples were obtained from eyes by capillary tube, centrifuged to obtain serum, which was analysed to compare the values of serum FT3, FT4 and TSH to the negative control rats. Hypothyroidism is defined as lower serum FT3, FT4 and higher TSH (Dons, et al., 2009).

\section{Diet Composition and Experimental Animal Design:}

The basal diet was formulated according to AIN-93M diet. Mineral mixture consisted of the recommended concentrations of elements for AIN-93M diet according to Reeves, et al., (1993). Sodium selenate was dissolved in distilled water before supplementation and was administrated with the basal diet in circular tiny amounts. After adaptation, rats were divided into two main groups as follows: The first main group (6 rats) was fed on basal diet and served as a negative control group (ve). The second main group (42 rats with hypothyroidism) was divided into seven subgroups (6 rats each) as follows: Subgroup (1) was fed on basal diet and served as a positive control group. Subgroup (2) was fed on basal diet supplemented with $0.05 \mathrm{mg}$ sodium selenate $/ \mathrm{kg}$ diet. Subgroup (3) was fed on basal diet supplemented with $0.18 \mathrm{mg}$ sodium selenate $/ \mathrm{kg}$ diet. Subgroup (4) was fed on basal diet supplemented with $5 \mathrm{mg}$ zinc carbonate/kg diet. Subgroup (5) was fed on basal diet supplemented with $10 \mathrm{mg}$ zinc carbonate / $\mathrm{kg}$ diet. Subgroup (6) was fed on basal diet supplemented with a mixture of $0.05 \mathrm{mg}$ sodium selenate and $5 \mathrm{mg}$ zinc carbonate/kg diet. Subgroup (7) was fed on basal diet supplemented with a mixture of $0.18 \mathrm{mg}$ sodium selenate and $10 \mathrm{mg}$ zinc carbonate $/ \mathrm{kg}$ diet. At the end of the experimental period (6 weeks), rats were sacrificed and blood samples were collected then centrifuged to separate the serum and kept frozen at $-20^{\circ} \mathrm{C}$ till analysis.

3. Biological Evaluation: Thyroid gland was removed from each rat, cleaned by a normal saline solution $(0.9 \%)$, dried by filtration paper and weighed. Thyroid gland weight was expressed as $(\mathrm{mg} / 100 \mathrm{~g} \mathrm{BW})$.

4. Biochemical Analysis of Serum: Free thyroxin (FT4), total T4, free triiodothyronine (FT3), total T3 and TSH hormones were measured in serum using ELISA assay method according to manufacturer's instruction (Rat FT4 ELISA Kit); (T4 rat ELISA, Catalog CSB-E05082r); (Rat FT3 ELISA Kit); (T3 rat ELISA, Catalog KA0925) and (TSH rat ELISA, 2012). This assay employs the competitive inhibition enzyme immunoassay technique. A polyclonal antibody specific for rat thyroid 
hormone has been pre-coated onto a microplate. Glutathione peroxidase (GPx) concentration was determined according to the method of Rotruck, et al., (1980). Selenium and zinc concentration were determined in serum using Atomic absorption spectroscopy (AAS) according to Sanders, (2015) for Se and Jian-Xin, (2010) for Zn.

5. Histopathological Examination: For histopathological study, the front of the necks of rats was dissected to extract the thyroid gland. The organ was immersed immediately in $10 \%$ neutral buffered formalin $\mathrm{pH} 7.4$ (Gamble, 2008). Photographs were taken using light microscope provided with digital camera. The histopathological examination was carried out at Pathology Department, Faculty of Veterinary Medicine, and Cairo University.

6. Statistical Analysis: The obtained data were statistically analyzed for significance using one-way analysis of variance "ANOVA". Computer Software system SPSS (Ver. 19) (SPSS, 1998) was used for these calculations. Results were expressed as mean $\pm \mathrm{SE}$ at $\mathrm{P} \leq 0.05$ significancy.

\section{RESULTS}

The present work was designed to evaluate the possible effect of selenium and/or zinc supplementation in the diet at two levels on thyroid hormones, GPx in experimentally induced hypothyroidism of adult male rats. Results illustrated in Table (1) indicate the effect of diet supplemented with Se and/or Zn on thyroid gland relative weight $(\mathrm{mg} / 100 \mathrm{~g} \mathrm{BW})$ of HT rats. The thyroid gland weight of the HT rats was significantly enlarged $(\mathrm{P} \leq 0.05)$ compared with the $(-\mathrm{ve})$ control group representing $17.06 \pm 0.48 \mathrm{mg} / 100 \mathrm{~g}$ BW vs. $7.56 \pm 0.41 \mathrm{mg} / 100 \mathrm{~g} \mathrm{BW}$, respectively. Rats ingested the tested diets containing the lowest level of either Se or Zn, had non-significant differences in thyroid gland weight compared with HT rats. Furthermore, diet supplemented with the highest level of either $\mathrm{Se}$ or $\mathrm{Zn}$ and their combination caused significant $(\mathrm{P} \leq 0.05)$ reduction in thyroid gland weight compared with the HT group (positive control). There were non-significant differences between these groups. It could be concluded that the combination of Se and $\mathrm{Zn}$ at the highest levels was the most effective level in the diet which gave the best reduction in the enlarged thyroid gland weight.

Table 1. Effect of Diet Supplemented with Selenium and/or Zinc on Thyroid Gland Relative Weight of Hypothyroid Rats.

\begin{tabular}{|c|c|}
\hline Groups & $\begin{array}{c}\text { Thyroid gland relative weight }(\mathrm{mg} / 100 \mathrm{~g} \\
\text { BW) }\end{array}$ \\
\hline Control (- ve) & $7.56 \pm 0.41^{\mathrm{d}}$ \\
\hline Control (+ ve) & $17.06 \pm 0.48^{\mathrm{a}}$ \\
\hline Se (0.05 mg/kg diet) & $15.55 \pm 0.82^{\mathrm{ab}}$ \\
\hline Se $(0.18 \mathrm{mg} / \mathrm{kg}$ diet $)$ & $14.17 \pm 0.29^{\mathrm{bc}}$ \\
\hline Zn (5 mg/kg diet) & $15.73 \pm 0.36^{\mathrm{ab}}$ \\
\hline $\mathrm{Zn}$ ( $10 \mathrm{mg} / \mathrm{kg}$ diet $)$ & $14.51 \pm 0.21^{\mathrm{bc}}$ \\
\hline$(0.05 \mathrm{mg} \mathrm{Se}+5 \mathrm{mg} \mathrm{Zn}) / \mathrm{kg}$ diet & $13.84 \pm 0.26^{\mathrm{c}}$ \\
\hline$(0.18 \mathrm{mg} \mathrm{Se}+10 \mathrm{mg} \mathrm{Zn}) / \mathrm{kg}$ diet & $12.99 \pm 0.68^{\mathrm{c}}$ \\
\hline
\end{tabular}

Mean values are expressed as means \pm SE. Means with different superscript letters in the column are significantly different at $\mathrm{P} \leq 0.05$.

Results of serum thyroid hormone profile are illustrated in Table (2). Both of FT4 and FT3 concentration in serum were significantly $(\mathrm{P} \leq 0.05)$ decreased as a result of PTU injection compared with the (-ve) control group. Furthermore, both of FT4 and FT3 serum concentration in HT rats were significantly $(\mathrm{P} \leq 0.05)$ increased following the administration of the different levels of either Se and/or Zn compared with the positive control group. Results showed that, there were no significant differences in the levels of FT4 and FT3 between the different levels of either Se and Zn. The results revealed that, the most pronounced increase of serum concentration of FT4 and FT3 was observed when rats were fed on diet supplemented with the combination of Se and $\mathrm{Zn}$. Results showed the same trend in both of serum concentration of FT4 and FT3.

Regarding to TSH results, serum level of TSH was significantly $(\mathrm{P} \leq 0.05)$ increased in the hypothyroid rats compared to the (-ve) control group which representing $6.44 \pm 1.33 \mathrm{ng} / \mathrm{ml}$ vs. $1.58 \pm 0.09 \mathrm{ng} / \mathrm{ml}$, respectively. Administration of Se and/or $\mathrm{Zn}$ in the diet at the two levels of intake to HT rats resulted in a significant $(\mathrm{p} \leq 0.05)$ reduction in TSH levels compared to the positive control group. It was observed that, there were no significant differences in TSH level in groups fed on either 
$\mathrm{Se}$ and/or $\mathrm{Zn}$ at the two levels of intake. It could be concluded that the two combination levels of Se and $\mathrm{Zn}$ provide the most effective levels in the diet which gave the best results concerning the concentration of TSH in serum.

Both of TT3 and TT4 concentration in serum were significantly $(\mathrm{P} \leq 0.05)$ decreased in the positive control group compared to the negative control group. Moreover, the highest level of either Se or $\mathrm{Zn}$ was significantly $(\mathrm{P} \leq 0.05)$ increased the mean value of serum TT3 concentration compared to the positive control group. Furthermore, the two combination levels of Se and $\mathrm{Zn}$ at the lower and high levels were significantly $(\mathrm{P} \leq 0.05)$ increased serum TT3 concentration as compared to the positive control group. Administration with either Se and/or Zn at the lowest and high levels in the diet to HT rats resulted in significant increase in serum TT4 levels as compared to the positive control group. It was shown that, the highest combination levels of Se and $\mathrm{Zn}$ was the most effective level in the diet which gave the best results in the serum concentration of both TT3 and TT4 compared with the negative control group.

Administration of Se and/or $\mathrm{Zn}$ in the diet at the two tested levels to HT rats caused an improving in the hypothyroid status as related to increasing the concentration of FT4, FT3 levels and decreasing the level of TSH.

Table 2. Effect of Diet Supplemented with Selenium and/or Zinc on Serum Thyroid Hormone Profile of Hypothyroid Rats.

\begin{tabular}{|c|c|c|c|c|c|}
\hline \multirow{2}{*}{ Groups } & \multicolumn{5}{|c|}{ Parameters } \\
\hline & FT3 (pg/dl) & FT4 (ng/dl) & TSH (ng/ml) & TT3 (ng/ml) & TT4 ( $\mu \mathrm{g} / \mathrm{dl})$ \\
\hline Control (- ve) & $4.00 \pm 0.05^{\mathrm{a}}$ & $3.24 \pm 0.09^{a}$ & $1.58 \pm 0.09^{\mathrm{c}}$ & $1.33 \pm 0.120^{\mathrm{a}}$ & $5.86 \pm 0.088^{a}$ \\
\hline Control (+ ve) & $1.92 \pm 0.06^{\mathrm{d}}$ & $1.27 \pm 0.14^{\mathrm{d}}$ & $6.44 \pm 1.33^{a}$ & $0.383 \pm 0.043^{\mathrm{e}}$ & $3.83 \pm 0.088^{f}$ \\
\hline Se $(0.05 \mathrm{mg} / \mathrm{kg}$ diet $)$ & $2.84 \pm 0.37^{\mathrm{c}}$ & $1.99 \pm 0.17^{\mathrm{c}}$ & $4.01 \pm 0.10^{b}$ & $0.530 \pm 0.030^{\mathrm{de}}$ & $4.57 \pm 0.090^{\mathrm{de}}$ \\
\hline Se $(0.18 \mathrm{mg} / \mathrm{kg}$ diet $)$ & $2.95 \pm 0.40^{\mathrm{c}}$ & $2.29 \pm 0.35^{\mathrm{c}}$ & $3.39 \pm 0.10^{b}$ & $0.643 \pm 0.012^{\mathrm{d}}$ & $4.78 \pm 0.091^{\mathrm{cd}}$ \\
\hline Zn (5 mg/kg diet) & $2.70 \pm 0.09^{c}$ & $2.24 \pm 0.09^{c}$ & $3.65 \pm 0.09^{b}$ & $0.497 \pm 0.008^{\text {de }}$ & $4.37 \pm 0.064^{\mathrm{e}}$ \\
\hline Zn ( $10 \mathrm{mg} / \mathrm{kg}$ diet $)$ & $3.22 \pm 0.16^{\mathrm{bc}}$ & $2.44 \pm 0.11^{\mathrm{bc}}$ & $3.39 \pm 0.14^{b}$ & $0.556 \pm 0.006^{\mathrm{d}}$ & $4.67 \pm 0.084^{\mathrm{d}}$ \\
\hline $\begin{array}{l}(0.05 \mathrm{mg} \mathrm{Se}+5 \mathrm{mg} \mathrm{Zn}) / \mathrm{kg} \\
\text { diet }\end{array}$ & $3.62 \pm 0.03 \mathrm{ab}^{\mathrm{ab}}$ & $2.89 \pm 0.01^{\mathrm{ab}}$ & $2.81 \pm 0.30^{b c}$ & $0.802 \pm 0.004^{\mathrm{c}}$ & $4.97 \pm 0.035^{b c}$ \\
\hline $\begin{array}{l}(0.18 \mathrm{mg} \mathrm{Se}+10 \mathrm{mg} \mathrm{Zn}) / \mathrm{kg} \\
\text { diet }\end{array}$ & $3.86 \pm 0.06 \quad a b$ & $2.88 \pm 0.17^{\mathrm{ab}}$ & $2.93 \pm 0.29^{b c}$ & $0.956 \pm 0.014^{\mathrm{b}}$ & $5.11 \pm 0.069^{b}$ \\
\hline
\end{tabular}

Mean values are expressed as means \pm SE.

Means with different superscript letters in the column are significantly different at $\mathrm{P} \leq 0.05$.

Table (3) illustrates the serum trace elements concentration of Se and $\mathrm{Zn}$ in experimental hypothyroid rats. PTU injection caused a significant reduction in the serum concentration of both Se and $\mathrm{Zn}$ compared with the (-ve) control group. When diet was supplemented with the two levels of Se intake, no significant differences were recorded in serum $\mathrm{Zn}$ concentration compared to the control positive group. Furthermore, the highest level of $\mathrm{Zn}$ intake was significantly $(\mathrm{P} \leq 0.05)$ increased the mean value of serum Se concentration as compared to the control positive group, although the low level of $\mathrm{Zn}$ intake caused non-significant differences compared to the control positive group. When diet was supplemented with the two combination levels of Se and $\mathrm{Zn}$, there was a significant increase in serum concentration of both $\mathrm{Se}$ and $\mathrm{Zn}$ as compared with the control positive group.

Table 3. Effect of Diet Supplemented with Selenium and/or Zinc on Serum Trace Elements and Glutathione Peroxidase Concentrations of Hypothyroid Rats

\begin{tabular}{|c|c|c|c|}
\hline \multirow[b]{2}{*}{ Groups } & \multicolumn{3}{|c|}{ Parameters } \\
\hline & $\operatorname{Se}(\mu \mathrm{g} / \mathrm{ml})$ & Zn (mg/l) & $\begin{array}{c}\text { GPx } \\
(\mathrm{mmol} / \mathrm{minute} / \mathrm{ml})\end{array}$ \\
\hline Control (- ve) & $0.826 \pm 0.020^{\mathrm{a}}$ & $2.84 \pm 0.05^{\mathrm{a}}$ & $3.86 \pm 0.16^{\mathrm{a}}$ \\
\hline Control (+ ve) & $0.653 \pm 0.024^{\mathrm{c}}$ & $1.24 \pm 0.03^{\mathrm{c}}$ & $0.47 \pm 0.03^{\mathrm{g}}$ \\
\hline Se (0.05 mg/kg diet) & $0.796 \pm 0.023^{\mathrm{a}}$ & $1.55 \pm 0.06^{\mathrm{c}}$ & $1.04 \pm 0.04^{\mathrm{f}}$ \\
\hline Se (0.18 mg/kg diet) & $0.833 \pm 0.026^{\mathrm{a}}$ & $1.56 \pm 0.32^{\mathrm{c}}$ & $1.54 \pm 0.07^{\mathrm{e}}$ \\
\hline Zn (5 mg/kg diet) & $0.683 \pm 0.020^{\mathrm{bc}}$ & $2.21 \pm 0.17^{\mathrm{b}}$ & $1.78 \pm 0.03^{\mathrm{e}}$ \\
\hline Zn ( $10 \mathrm{mg} / \mathrm{kg}$ diet) & $0.726 \pm 0.023^{b}$ & $2.57 \pm 0.07^{\mathrm{ab}}$ & $2.18 \pm 0.02^{d}$ \\
\hline$(0.05 \mathrm{mg} \mathrm{Se}+5 \mathrm{mg} \mathrm{Zn}) / \mathrm{kg}$ diet & $0.816 \pm 0.008^{a}$ & $2.66 \pm 0.07^{\mathrm{ab}}$ & $2.58 \pm 0.06^{\mathrm{c}}$ \\
\hline$(0.18 \mathrm{mg} \mathrm{Se}+10 \mathrm{mg} \mathrm{Zn}) / \mathrm{kg}$ diet & $0.853 \pm 0.031^{\mathrm{a}}$ & $2.79 \pm 0.28^{\mathrm{a}}$ & $3.46 \pm 0.11^{b}$ \\
\hline
\end{tabular}


Mean values are expressed as means \pm SE. Means with different superscript letters in the column are significantly different at $\mathrm{P} \leq 0.05$.

Results of serum glutathione peroxidase enzyme of hypothyroid rats are illustrated in Table (3). The mean GPx concentration of the HT control rats was significantly decreased as compared to the (-ve) control group. In addition, the GPx concentration of hypothyroid rats administered the tested diets containing the two levels of $\mathrm{Se}$ and/or $\mathrm{Zn}$ of intake were significantly $(\mathrm{P} \leq 0.05)$ increased as compared to the positive control group. Furthermore, the highest level of either Se or $\mathrm{Zn}$ or their highest combination levels of intake were significantly $(\mathrm{P} \leq 0.05)$ increased serum GPx concentration compared to the lowest level of both of them. The GPx concentration in serum of rats fed on the highest combination levels of Se and $\mathrm{Zn}$ showed the best results among all tasted groups compared to the (-ve) control group. It could be concluded that, administration of Se and/or $\mathrm{Zn}$ in the diet at the two tested levels to hypothyroid rats increased the concentration of both $\mathrm{Se}$ and $\mathrm{Zn}$ antioxidants. Results in increasing antioxidant biomarker level which representing in GPx concentration.

\section{Histopathological Examination of Thyroid Gland}

Microscopically, thyroid gland of the (-ve) control rats fed on basal diet revealed normal histopathological structure of thyroid gland (Photo1). Meanwhile, thyroid gland of rat from control positive group (HT rats) showed obvious changes such as enlarged and dilated thyroid follicles lined with flattened epithelium and congested capilleries (Photo 2). This study demonstrated that PTU exerted harmful effects on the histopathological structure and the function of the thyroid gland (hypothyroidism). Thyroid gland of the HT group fed on diet supplemented with low Se level (Photo 3) revealed changes in the thyroid gland tissue including congested capilleries. Also, the hypothyroid group fed on diet supplemented with high Se level (Photo 4) revealed dilatation and congestion of blood vessels. Moreover, hypothyroid group fed on diet supplemented with rats fed on $\mathrm{Zn}$ at low or high levels (Photo 5) showed dilated follicles with congested capilleries. Interestingly, administration of Se and $\mathrm{Zn}$ at the two combination levels of intake (Photo 6) caused improving in hypothyroid status. These related to show significant decrease epithelial height and showed no histopathological changes when compared to the control (-ve) group.

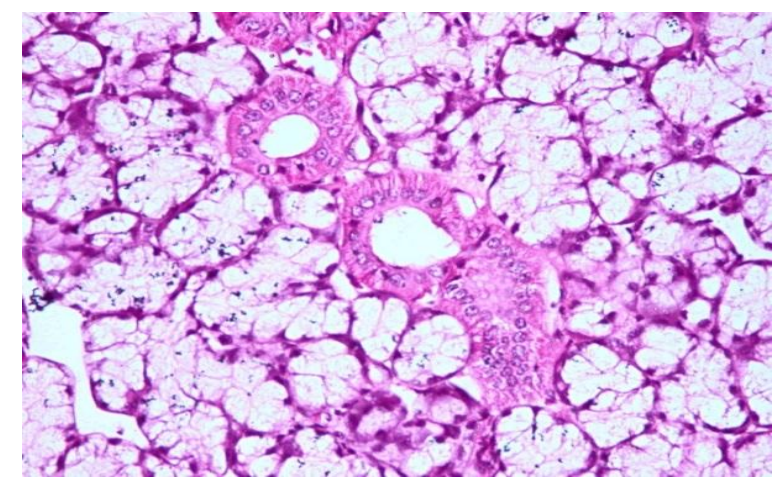

Photo (1). Thyroid gland of rats from the negative control group showing normal follicles with normal lining epithelium. (H\&E X 400).

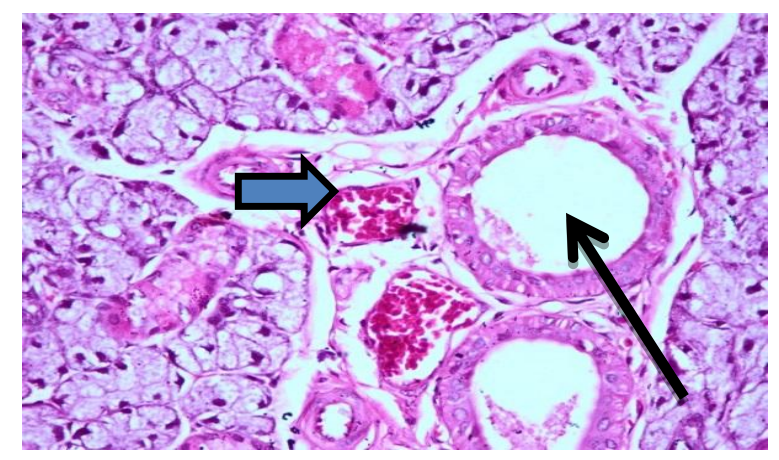

Photo (2). Thyroid gland of rats from the positive control group showing enlarged and dilated follicles (arrow) lined with flattened epithelium and congested capilleries (arrow head). (H\&E X 400). 
Hoda S. Ibrahim et al.

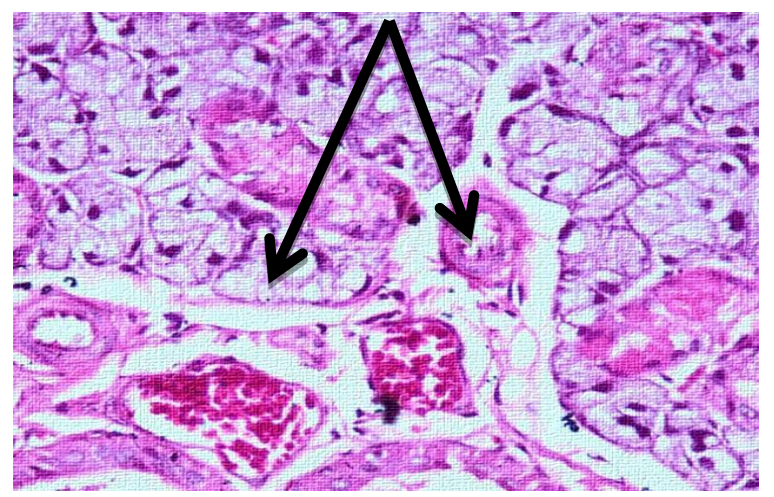

Photo (3). Thyroid gland of HT rats fed on Se at the lowest tested level showing congested capilleries (arrow). $(H \& E X 400)$.

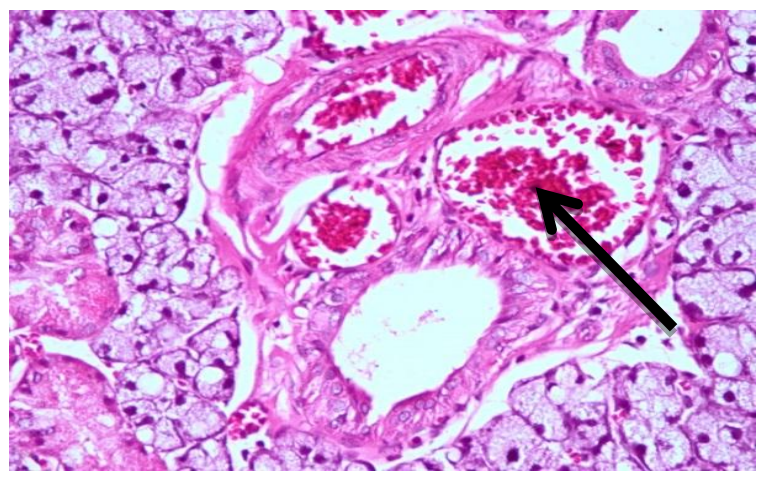

Photo (4). Thyroid gland of HT rats fed on Se at the highest tested level showing marked dilatation and congestion of blood vessels ( $H \& E X 400)$.

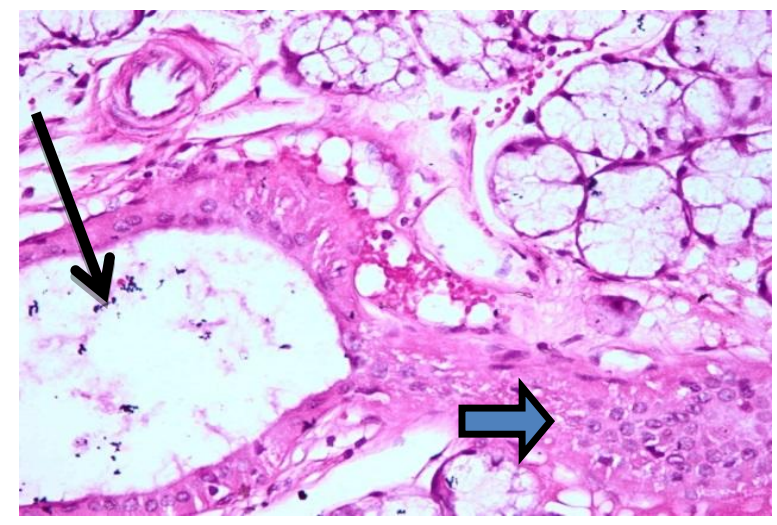

Photo (5). Thyroid gland of HT rats fed on Zn at the two tested levels showing dilated follicles (arrow) with congested capilleries (arrow head). (H\&E X 400).

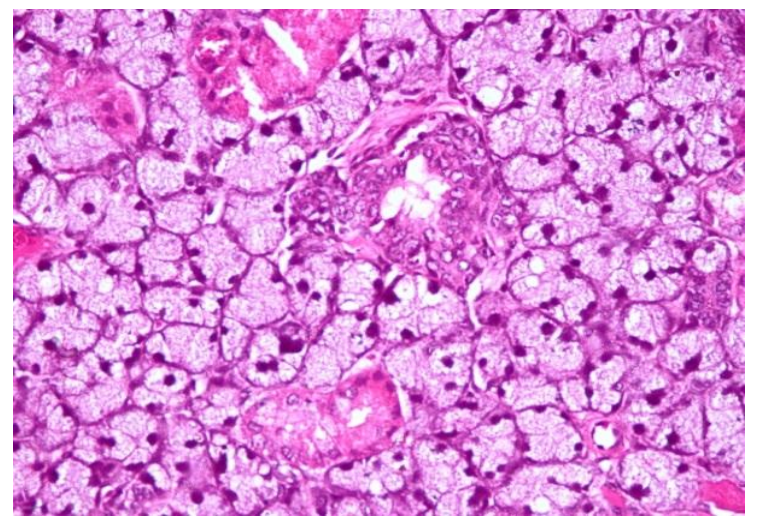

Photo (6). Thyroid gland of HT rats fed on at the two tested levels of Se + Zn showing no histopathological changes. (H\&E X 400). 


\section{DISCUSSION}

Hypothyroidism is a metabolic disorder which is proved biochemically by the significant decrease in the serum levels of triiodothyronine and thyroxine (Amara, et al., 2010). The correlated findings of thyroid histopathology and thyroid hormone imbalance show a hypothyroidism by a great decrease in serum FT4 and FT3 levels. The increased serum TSH levels, thyroid weights and the thyroid hyperplasia are consistent with a consequent stimulation of pituitary cells. The enlargements in thyroid weights in this study (Table 2) are also similar to those described by Ampong, et al., (2002) and Amara, et al., (2010). These effects were reversed at least in part when the diet was supplemented with Se. The obtained results are in agreement with the finding of Amara, et al., (2010), who found the addition of Se to diet had a partial recovery occurred in body and thyroid gland weights and plasma TSH levels of both mothers and pups. Furthermore, Rasmussen, et al., (2011) who showed an inverse relationship between the serum Se concentration and the volume of the thyroid gland, reported that Se supplementation found to be significantly associated with thyroid volume regression in autoimmune thyroiditis.

In the present study, PTU treated rats showed hypothyroidism. The mechanism for this response is an increase in TSH levels due to a decrease in the production of thyroid hormone FT4, FT3 (Sener, et al., 2006). This was evidenced biochemically by reduction in serum thyroid hormone levels of FT4, FT3, TT3 and TT4 with increase in serum TSH level compared to the normal control rats. These results are in agreement with Rabeh and El-Ghandour, (2016) who found that PTU exposed rats showed significant decrease in serum T3 and T4 levels with significant increase in serum TSH level. Also, confirmed by Sener, et al., (2006) who reported that PTU dramatically reduced thyroid hormones. Serum concentrations of thyroid hormones T3, T4 and TSH are commonly used as reliable indicators of the thyroid function in humans and experimental animals (Kelly, 2000). Propylthiouracil effects may be due to inhibiting the thyroid hormone synthesis and blocking the transformation of T4 to T3 (Ökten, et al., 1996). Deiodinase is strongly inhibited by the anti-thyroid drug PTU (Norris, 2007). As the prohormone $T 4$ is then converted to its biologically active form $T 3$ by iodothyronine deiodinase (Bianco, et al., 2002). Furthermore, Zbucki, et al., (2007) who found a significant decrease in the plasma concentration of T3 and T4 of HT rats whereas TSH level was significantly increased compared to the negative control rats.

The obtained results concerning Se supplementation increasing serum thyroid hormone levels of FT4, FT3, TT3 and TT4 could be explained by Rayman, (2000) who suggested that Se supplementation improved conversion of T4 to T3. Chanoine, (2001) extracted that one possible explanation for these findings, that the iodothyronine 5'deiodinases is selenoenzyme. In compendium, when Se is depleted, there is less Se to form the 5'deiodinase enzymes, resulting in low T3 and hypothyroidism. This was supported by an interventional trial in trauma patients where it was shown that a substitution with sodium selenite normalizes TT3 levels earlier compared with controls (Angstwurm, et al., 2004). The obtained study showed that the hypothyroid state, induced by PTU, could be prevented by Se supplementation in diet. This finding was supported by Amara, et al., (2010) who found that when selenium was supplemented to the diet of methimazole -treated rats, concentration of plasma FT4 and FT3 increased. Furthermore Erdal, et al., (2008), who indicated the important role of Se in controlling the thyroid gland functions. This trace element can be of great fundamental importance to health since it activates thyroid hormone synthesis. On the other hand, Combs, et al., (2009) and Thomson, et al., (2011) reported that no changes were found in the concentrations of TSH, FT3 or FT4 concentrations, apart from a non-significant increase in FT3 in this cohort of patients in response to selenium supplements. Another study demonstrated the absence of significant influence of Se on the FT3, FT4, TSH levels (Ravaglia, et al., 2000) this contradiction in the results could be due to many factors such as the duration of the study .

Zinc has important roles in thyroid metabolism (Dhawan, et al., 2007 and Baloch, et al., 2013). The obtained results indicated that diet supplementation with $\mathrm{Zn}$ increased serum thyroid hormone levels. These are in agreement with Rabeh and El-Ghandour, (2016) who found that the supplementation with Zn significantly increased the concentration of thyroid hormone FT4 and FT3 and also caused a significant decrease in TSH, compared with the control positive group. Similar results were found by Nishiyama, et al., (1994) who mentioned that $\mathrm{Zn}$ plays a role in $\mathrm{TH}$ metabolism and in the conversion of T4 to T3. Moreover, Freake, et al., (2001) who reported that there is evidence that $\mathrm{Zn}$ 
deficiency results in a reduction in conversion of $\mathrm{T} 4$ to $\mathrm{T} 3$, and in turn $\mathrm{T} 3$ requires $\mathrm{Zn}$ to fulfill its biological activity.

Zinc-induced reduction in thyroid hormone could be due to its effects on deiodinase activity through its antioxidant properties (Vrca, et al., 2004). Pekary, et al., (1991) extracted that $\mathrm{Zn}$ involves in T3 binding to its nuclear receptor. Napolitano, et al., (1990) found that, $\mathrm{Zn}$ application increased thymic functions and this in turn, improved thyroid functions influencing the pituitary-thyroid axis. Moreover, Zn status and serum TH levels were improved in goitrous patients after six months treatment with Zn supplementation (Kandhro, et al., 2009). Zinc supplementation improved thyroid function in nine patients with low Zn levels (Napolitano, et al., 1990). An attempt to link the low levels of TH and $\mathrm{Zn}$ is worthwhile. The metabolism of $\mathrm{Zn}$ and thyroid hormone are closely interlinked (Betsy, et al., 2013) who also reported that $\mathrm{Zn}$ deficiency may have contributed significantly to the development of HT. In a group of patients with low levels of FT3, normal T4 and mild to moderate $\mathrm{Zn}$ deficiency, taking oral Zn supplements for 12 months, normalized the serum FT3, TT3 and normalized TSH levels (Nishiyama, et al., 1994). On the other hand, suppression of T3 and T3/T4 was found in a study in which rats were supplemented with $\mathrm{Zn}$ chloride, due to a reduction in microsomal capacity to convert T4 to T3 (Moustafa, 2001). The obtained results are not consistent with these reports. In the present study, Zn generally led to an increase in thyroid hormone levels. The discrepancy may be explained by differences in the manner, duration and type of $\mathrm{Zn}$ administration.

Hypothyroid group had lowest Se and $\mathrm{Zn}$ concentration in serum as compared with administrated groups with $\mathrm{Se}$ and/or $\mathrm{Zn}$ and the normal control groups in the study. The possible explanation for these findings as observed by Bellisola, et al., (1998) is due to the significant influence of TSH in the variation of the concentration of iodine, $\mathrm{Se}$ and $\mathrm{Zn}$ in normal and altered human thyroid tissues. The decrease in serum Se levels in HT status are in agreement with the studies of other researchers by Kucharzewski, et al., (2002) who found that when patients suffering from various forms of thyroid disease were tested for Se levels, all were found to be lower than normal healthy people. The results of present study indicated that there is an increase of serum Se concentration in the tested groups as compared with the hypothyroid group. These are in harmony with the results of Dharmasena, (2014) who reported that the Se concentrations in whole blood correlate directly with the dietary Se intakes. The obtained results concerning lower serum $\mathrm{Zn}$ concentration in HT status are in the line with results of different researches such as Zhang, et al., (2004) who suggested that, the one possible explanation for these findings that gastrointestinal absorption of $\mathrm{Zn}$ is severely impaired in HT subjects. Chen, et al., (2005) also reported that hypothyroid reduces intestinal $\mathrm{Zn}$ absorption in rats. Baloch, et al., (2013) suggested that, there is an abnormal metabolism of $\mathrm{Zn}$ in hypothyroid disease. And suggested an alternative explanation would be a change in $\mathrm{Zn}$ distribution; the low $\mathrm{Zn}$ level may reflect sequestration of $\mathrm{Zn}$ by the liver or other tissues. Also these are in the line with Baltaci, et al., (2013) who found that, the lowest $\mathrm{Zn}$ levels were obtained in the hypothyroid group. In a study including 34 HT patients, serum Zn content was shown to be remarkably decreased (Buchinger, et al., 1988).

In the present study PTU treated rats showed hypothyroidism with significant reduction in serum glutathione peroxidase concentration compared the normal rats as shown in Table3. These results are in harmony with Rabeh and El-Ghandour, (2016) who found that, there was a significant decrease in the concentration of GPx as a result of PTU injection, compared with (-ve) control group. Antioxidants treatments might be helpful in reducing the oxidative damage due to hypothyroidism (Erdamar, et al., 2008). The obtained results demonstrated that, supplementation with Se and/or $\mathrm{Zn}$ in the diet caused a significant increase in serum GPx concentration compared to HT rats. Thomson, et al., (2011) demonstrated a significant increase in plasma Se and whole blood GPx activity with a daily supplementation of $100 \mu \mathrm{g}$ L-selenomethionine for $12 \mathrm{wk}$. Mazokopakis and Chatzipavlidou, (2007) suggested the one possible explanation for these findings. This may be due to the increase in GPx and thioredoxin reductase activity, as well as the decrease in toxic concentrations of hydrogen peroxide and lipid hydroperoxides which result from TH synthesis. The obtained results showed that diet supplementation with zinc caused a significant increase in serum GPx concentration compared to HT rats. These are in harmony with Rabeh and El-Ghandour, (2016) who found that, the level of GPx was significantly increased in group fed on Zn supplementations compared with HT rats. And also reported that, supplementation with antioxidant $\mathrm{Zn}$ was able to support the activities of antioxidant enzymes during hypothyroid leading to delay the development of oxidative disease. 
The biochemical results confirmed the histopathological aspects of the thyroid glands. In the present study it was observed histopathological changes in the thyroid gland of PTU-treated rats. There were characterized by follicular cell hyperplasia suggestive of an enhanced thyroid activity, an increase in follicular number and vascularity and a decrease in colloid. Hypothyroidism was proved histopathologicaly by the large follicles over distended with colloid with minimal scalloping and lined with flattened cells, the degenerated follicular cells and loss of microvilli (El-Mehi and Amin, 2012). The thyroid gland is the only organ involved in T4 synthesis (Kelly, 2000). The decrease of this hormone level in the serum of the PTU injected rats, may suggest that PTU influences the production and/or secretion of T4 by follicular cells. That might be related to structural damage of thyroid follicular cells due to accumulation of PTU in the thyroid gland. The results of Badiei, et al., (2009) and El-Mehi and Amin, (2012) support this view as it showed lead induced apoptotic changes of thyroid follicular cells. The obtained results indicated that the effect of selenium supplementation improved histopathological examination of thyroid gland. These are in harmony with those of Amara, et al., (2010) who found that Se supplementation improved the histopathological features of the thyroid gland. Evidenced by its return to normal aspects in which the phenomena of proliferation and cell death must have been involved. However, highest TH plasma levels occurred in (methimazole + $\mathrm{Se})$ group, exerting a negative feedback on the pituitary which reduced TSH levels. Restoring iodide, after selenium supplementation to diet, reduced the hypertrophy of follicle epithelial cells and increased the colloidal volume. In a more complex study with combined Se, iodine and $\mathrm{Zn}$ deficiencies, there was an interaction between $\mathrm{Se}$ and $\mathrm{Zn}$ deficiencies on thyroid follicle cell architecture, which was compatible with apoptosis (Ruz, et al., 1999). Selenium supplementation improves the ultrasound structure of the thyroid gland (Drutel, et al.,2013).

\section{CONClusion}

It could be suggested that $\mathrm{Zn}$ and Se at the tested levels and its mixture could be used as a suitable supplementation therapy for hypothyroid patients. It is important to assess the selenium and zinc status of the individual patients prior to $\mathrm{Se}$ and $\mathrm{Zn}$ supplementation and at regular intervals while on treatment. Inorganic forms of selenium (i.e., sodium selenite and sodium selenate) may be toxic at high doses so, the organic forms are recommended.

\section{REFERENCES}

Amara, I.B.; Bouaziz, H.; Guermazi, F. and Zeghal, N. (2010): "Effect of selenium on hypothyroidism induced by methimazole (MMI) in lactating rats and their pups", Acta Biologica Hungarica., 61(2), pp: 145-157.

Ampong, B.; Honda, H. and Kogo, H. (2002): "Effect of hypothyroidism on $\beta$-adrenoreceptormediated relaxation in the rat thoracic aortae: A time-dependent study." Vascul Pharmacol., 38: 149-155.

Angstwurm, M.W.; Schopohl, J. and Gaertner, R. (2004): "Selenium substitution has no direct effect on thyroid hormone metabolism in critically ill patients." Eur J Endocrinol., 151(1):47-54.

Badiei, K.; Nikghadam, P.; Mostaghni, K. and Zarifi, M. (2009): "Effect of lead on thyroid function in sheep." Iranian Journal of Veterinary Research, 10 (3):223-227.

Baloch, S.; Memon, A.R.; Hayat, A.S. and Masood, N. (2013): "Evaluation of Serum Copper and Zinc in Hypothyroidism." ARPN Journal of Science and Technology, (3):316-318.

Baltaci, A.K.; Mogulkoc, R. and Belviranli, M. (2013): "Serum levels of some elements relative to zinc in induced hypothyroidism." Acta Clin Croat, 52:151-156.

Beckett, G.J. and Arthur, J.R. (1994): "The lodothyronine deiodinases and 5'-deiodination." Baillieres Clin Endocrinol Metab, 8: 285-304.

Bellisola, G.; Bratter, P.; Cinque, G.; Francia, G.; Galassini, S. and Gawlik, D. (1998): "The TSH-dependent variation of the essential elements iodine, selenium and zinc within human thyroid tissues" Journal of Trace Elements in Medicine and Biology, 12(3): 177-182.

Betsy, A.; Binitha, M.P. and Sarita, S. (2013): "Zinc Deficiency Associated with Hypothyroidism: An Overlooked Cause of Severe Alopecia" nt J. Trichology., 5(1): 40-42.

Bianco, A. C.; Salvatore, D.; Gereben, B.; Berry, M. J. and Larsen, P. R. (2002): Endocr. Rev. 23: 38 . 
Buchinger, W.; Leopold, B.; Lind, P.; Langsteger, W. and et al., (1988): "Changes in zinc level in the serum, whole blood and erythrocytes in disorders of thyroid function." Wien Klin Wochenschr, 100:619-621.

Catania, A. S.; Barros, C. R. and Ferreira, S. R. (2009): "Vitamins and minerals with antioxidant properties and cardio metabolic risk: controversies and perspectives", Endocrinol. Metabol, 53: 550-559.

Chanoine J.P. (2001): "Selenium decreases thyroglobulin concentrations but does not affect the increased thyroxin-totriiodothyronine ratio in children with congenital hypothyroidism." Journal of Clinical Endocrinology and Metabolism, 86(3): 1160-1163.

Chen, S.M.; Kuo, C.D.; Ho, L.T. and Liao, J.F. (2005): "Effect of hypothyroidism on intestinal zinc absorption and renal zinc disposal in five-sixths nephrectomized rats." Jpn J Physiol., 55:211-219.

Combs, G.F.; Midthune, D.N.; Patterson, K.Y., and et al. (2009): "Effects of selenomethionine supplementation on selenium status and thyroid hormone concentrations in healthy adults." Am. J. Clin Nutr., 89: 1808-1814.

Dharmasena, A. (2014): "Selenium supplementation in thyroid associated ophthalmopathy: an update", Int J Ophthalmol., 7(2):365-375.

Dhawan, D.; Singh, B.M. and Dani, V. (2007): "Zinc sulfate following the administration of iodine131 on the regulation of thyroid functions, in rats." Hell Journal of Nuclear Medicine, 10(3):167171.

Dons, Robert, F.; Frank, J. and Wians, H. (2009): "Endocrine and Metabolic Disorders Clinical Lab Testing Manual (4th ed.)", Boca Raton: CRC Press. P: 10.

Drutel, A.; Archambeaud, F. and Caron, P. (2013): "Selenium and the thyroid gland: more good news for clinicians", Clinical Endocrinology (Oxf), 78: 155-164.

El-Mehi, A.E. and Amin, S.A. (2012): "Effect of Lead Acetate on the Thyroid Gland of Adult Male Albino Rats and the Possible Protective Role of Zinc Supplementation: A Biochemical, Histological and Morphometric Study", Journal of American Science, 8(7):61-71.

Erdal, M.; Sahin, M., Hasimi, A.; Uckaya, G.; Kutlu, M. and Saglam, K. (2008): "Trace element levels in hashimoto thyroiditis patients with subclinical hypothyroidism", Biological Trace Element Research, 123(1-3):1-7.

Erdamar, H.; Demirci, H.; Yaman, H.; Erbil, M. K., and et al. (2008): "The effect of hypothyroidism, hyperthyroidism, and their treatment on parameters of oxidative stress and antioxidant status", ClinChem Lab Med., 46: 1004-1010.

Fabrizio, M. (2003): "Classification of thyroid diseases: suggestions for a revision", J. Clin. Endocrinol Metab., 88(4): 1428-32.

Fetoui, H.; Bouaziz, H.; Mahjoubi-Samet, A.; Soussia, L.; Guermazi, F. and Zeghal, N. (2006): "food restriction induced thyroid changes and their reversal after refeeding in female rats and their pups", Acta Biol. Hung., 57: 391-402.

Formigari, A.; Irato, P. and Santon, A. (2007): "Zinc, antioxidant systems and metallothionein in metal mediated-apoptosis: biochemical and cytochemical aspects", Comp Biochem Physiol C Toxicol Pharmacol, 146:443-459.

Freake, H.C.; Govoni, K.E.; Guda, K.; Huang, C. and Zinn, S.A. (2001): "Actions and interactions of thyroid hormone and zinc status in growing rats." J Nutr, 131:1135-1141.

Gamble, B.J. (2008): " Theory and Practice of Histology Techniques (6 ed.)", Churchill Livingstone Elsevier., China 72.

Garber, J.R.; Cobin, R.H.; Gharib, H., and et al. (2012): "Clinical Practice Guidelines for Hypothyroidism in Adults" Thyroid, 22 (12): 1200-1235.

Ghorbel, H.; Fetoui, H.; Mahjoubi, A.; Guermazi, F. and Zeghal, N. (2008): "Thiocyanate effects on thyroid function of weaned mice", C. R. Biol., 331: 262-271.

Golden, S.H.; Robinson, K.A.; Saldanha, I.; Anton, B. and Ladenson, P.W. (2009): "Clinical review: Prevalence and incidence of endocrine and metabolic disorders in the United States: a comprehensive review", J Clin Endocrinol Metab., 94:1853-78. 
Jian-Xin, Q. (2010): "Determination of $\mathrm{Cu}, \mathrm{Zn}, \mathrm{Fe}, \mathrm{Ca}, \mathrm{Mg}, \mathrm{Na}$ and $\mathrm{K}$ in Serum by Flame Atomic Absorption Spectroscopy, Agilent Technologies", Hunan Medical University, Changcha, China (AA093).

Kandhro, G.; Kazi, T.; Afridi, H.; Kazi, N.; Baig, J.; Arain, M. and et al., (2009): "Effect of Zinc supplementation on the Zinc level in serum and urine and their relation to thyroid hormone profile in male and female goitrous patients", Clinical Nutrition., 28 (2): 162-168.

Kelly, G.S. (2000): "Peripheral metabolism of thyroid hormones: a review", Altern Med Rev. 5:306333.

Kucharzewski, M.; Braziewicz, J.; Majewska, U. and Gozdz, S. (2002): "Concentration of selenium in the whole blood and the thyroid tissue of patients with various thyroid diseases", Biol Trace Elem Res., 88(1):25-30.

Mahjoubi-Samet, A.; Fetoui, H.; Soussia, L.; Guermazi, F. and Zeghal, N. (2005): "dimethoate effects on thyroid function in suckling rats", Ann. Endocrinol., 66: 96-104.

Maxwell, C. and Volpe, S.L. (2007): "Effect of zinc supplementation on thyroid hormone function: A case study of two college females", Ann Nutr Metab., 51:188-194.

Mazokopakis, E.E. and Chatzipavlidou, V. (2007): "Hashimoto's thyroiditis and the role of selenium: Current concepts", Hellenic Journal of Nuclear Med., 10(1): 6-8.

Moustafa, S.A., 2001: "Effect of glutathione (GSH) depletion on the serum levels of triiodothyronine (T3), thyroxine (T4), and T3/T4 ratio in allyl alcohol-treated male rats and possible protection with Zinc", Int. J. Toxicol., 20: 15-20.

Napolitano, G.; Palka, G.; Lio, S, Bucci, I.; De Remigis, P. and et al., (1990): "Is zinc deficiency a cause of subclinical hypothyroidism in Down syndrome?" Ann Genet., 33:9-15.

Nishiyama, S.; Futagoishi-Suginohara, Y.; Matsukura, M. and et al., (1994): "Zinc supplementation alters thyroid hormone metabolism in disabled patients with zinc deficiency", $\mathbf{J}$ Am Coll Nutr, 13(1):62-67.

Norris, D.O. (2007): Vertebrate Endocrinology.4th ed. Elsevier Inc.

Ökten, A.; Mungan, Z. and Onuk, M.D. (1996): "A case of propylthiouracil induced hepatotoxicity and hemolytic anemia", Tur J Gastroenterol., 7: 82-85.

Pekary, A.E.; Lukaski, H.C.; Mena, I. and Hershman, J.M. (1991): "Processing of TR.H precursor peptides in rat brain and pituitary is zinc dependent", Peptides, 12:1025-1032.

Prasad, A.S. (2013): "Discovery of human Zinc deficiency: Its impact on human health and disease", Adv. Nutr., 4: 176-190.

Rabeh, N.M. and El-Ghandour, H.A. (2016): "Effect of Iron, Zinc, Vitamin E and Vitamin C Supplementation on Thyroid Hormones in Rats with Hypothyroidism", International Journal of Nutrition and Food Sciences, 5(3): 201-210.

Rasmussen, L.B.; Schomburg, L.; Köhrle, J.; Pedersen, I.B. and et al., (2011): "Selenium status, thyroid volume, and multiple nodule formation in an area with mild iodine deficiency", Eur $\mathbf{J}$ Endocrinol., 164(4):585-90.

Rat FT3 ELISA Kit: Rat Free Tri-iodothyronine Indes (Catalog. No. CSB-E05076r) Instruction manual, Cusabio Co.,Ltd.

Rat FT4 ELISA Kit: Enzyme-linked immuneosorbent assay Kit, Catalog. No.: E90185Ra, For Rat Free Thyroxine (FT4) Instruction manual, USCN Business Co., Ltd.

Ravaglia, G.; Forti, P.; Maioli, F.; Nesi, B.; Pratelli, L. and et al., (2000): "Blood micronutrient and thyroid hormone concentrations in the oldest-old", J Clin Endocrinol Metab., 85(6):22602565 .

Rayman, M.P. (2000): "The importance of selenium to human health", Lancet, 356(9225):233-241.

Reeves, G., Nielsen, and Fahey, C. (1993): "AIN-93 purified diets for laboratory rodents: final report of the American institute of nutrition ad hoc writing committee on the reformulation of the AIN-76A rodent diet", J. Nutr. 123:1939-1951.

Rotruck, J.T.; Pope, A.L.; Ganther, H.E.; Swanson, A.B. and et al., (1980): "Selenium: biochemical role as a component of glutathione peroxidase, purification and assay", Nutrition Reviews, Science, 38: (8) 280-283. 
Ruz, M.; Codoceo, J.; Galgani, J. and et al. (1999): "Single and multiple selenium-zinc-iodine deficiencies affect rat thyroid metabolism and ultrastructure", J Nutr., 129: 174-180.

Sanders, j. (2015): "Selenium in serum measured by Zeeman graphite furnance Atomic Absorption Spectroscopy", Agilent Technologies, Melbourne, Australia, (AA122).

Sener, G.; Kabasakal, L.; Atasoy, B.M.; Erzik, C. and et al., (2006): " Propylthiouracil-induced hypothyroidism protects ionizing radiation-induced multiple organ damage in rats", Journal of Endocrinology, 189: 257-269.

SPSS (1998): Statistical Package for Social Science. Computer Software, (Ver. 19.), SPSS Company, London, UK.

T3 rat ELISA, Catalog KA0925: T3 (Total) (Mouse/Rat) ELISA Kit Version 02: Manufacture instruction manual, Catalog Number: KA0925, Abnova Company.

T4 rat ELISA, Catalog CSB-E05082r: Rat thyroxine (Catalog No.CSB-E05082r): Manufacture instruction manual, Cusabio Co.,Ltd.

The British Nutrition Foundation. (2001): Briefing Paper. www. Nutrition.Org.UK.

Thomson, C.D.; Campbell, J.M.; Miller, J. and Skeaff, S.A. (2011): "Minimal impact of excess iodate intake on thyroid hormones and selenium status in older New Zealanders", Eur J Endocrinol., 165(5):745-752.

TSH rat ELISA, (2012): Thyroid Stimulating Hormone for Rat, Version: 1a-07/11 120704, Manufacture instruction manual, Catalog NO: 55-TSHRT-E0, ALPCO Diagnostics Co., Ltd.

Vrca, V.B.; Skrebb, F.; Cepelakc, I.; Romicd, Z. and Mayerd, L. (2004): "Supplementation with antioxidants in the treatment of Grave' $\mathrm{s}$ disease; the effect on glutathione peroxidase activity and concentration of selenium", Acta. Clin Chim., 341: 55-63.

Zbucki, R.; Winnicka, M.; Sawicki, B.; Szynaka, B. and et al., (2007): "Alteration of parafollicular (C) cells activity in the experimental model of hypothyroidism in rats". Folia Histochemica et Cytobiologica, 45(2):115-121.

Zhang, F.; Liu, N.; Wang, X.; Zhu, L. and Chai, Z. (2004): "Study of trace elements in blood of thyroid disorder subjects before and after 131I therapy", Biol Trace Elem Res., 97:125-134.

Zimmermann, M.B. (2008): "Iodine requirements and the risks and benefits of correcting iodine deficiency in populations", J. Trace Elem. Med. Biol., 22: 81-92. 